\title{
Impact of polymer blending on Ionic Conduction Mechanism and Dielectric Properties of Sodium based PEO-PVdF Solid Polymer Electrolyte Systems
}

\section{Yalla Mallaiah}

Osmania University

\section{VENKATA RAMANA JEEDI}

B V Raju Institute of Technology

\section{R. Swarnalatha}

Osmania University

\section{A. Raju}

Kakatia Univerity

\section{S. Narender Reddy}

Stanley college of Engineering and Technology for women

SADANANDA CHARY A ( $\nabla$ asadanandachary60@gmail.com )

Osmania University https://orcid.org/0000-0003-3308-7010

\section{Research Article}

Keywords: Blend polymer electrolyte, solution cast technique, XRD, FTIR, SEM, impedance analysis, Nyquist plots

Posted Date: February 19th, 2021

DOI: https://doi.org/10.21203/rs.3.rs-239135/v1

License: (c) (i) This work is licensed under a Creative Commons Attribution 4.0 International License. Read Full License 


\title{
Impact of polymer blending on Ionic Conduction Mechanism and Dielectric Properties of Sodium based PEO-PVdF Solid Polymer Electrolyte Systems
}

\author{
Yalla Mallaiah ${ }^{1}$, Venkata Ramana Jeedi ${ }^{2}$, R. Swarnalatha ${ }^{3}$, A. Raju ${ }^{4}$, S. Narender Reddy ${ }^{5}$ A. Sadananda Chary ${ }^{6}$ \\ ${ }^{1}$ Department of Physics, University PG College, Secunderabad, Osmania University, Hyderabad \\ ${ }^{2}$ Department of Physics, B V Raju Institute of Technology, Narsapur, Medak Dist, 502313 \\ ${ }^{3}$ Department of Physics, University College of Engineering (A), Osmania University, Hyderabad \\ ${ }^{4}$ University Arts \& Science College, Kakatia Univerity, Warangal, Telangana, 506001 \\ ${ }^{5}$ Stanley college of Engineering and Technology for women, Abids, Hyderabad \\ ${ }^{6}$ Department of Physics, University College of Science, Osmania University, Hyderabad
}

\begin{abstract}
:
Solid polymer blend electrolyte systems have been prepared with Poly (ethylene oxide) (PEO), Poly (Vinylidene fluoride) (PVDF) and complexed with Sodium Nitrate $\left(\mathrm{NaNO}_{3}\right)$ salt by using solution cast technique. The complexion of salt with polymer blend has been confirmed by X-Ray diffraction, Fourier Transmission Infrared Spectroscopy and scanning electron microscopic studies. AC and DC conductivity studies of these polymer blends were carried out by changing the weight percentages of PEO and PVDF with a constant weight percentage of $\mathrm{NaNO}_{3}$. The electric modulus $\left(\mathrm{M}^{\prime}\right)$ and the dielectric properties for all the polymer blend systems have been investigated with impedance spectroscopic analysis as a function of frequency ranging from 100-30MHz. The ionic conductivity of the blend polymer electrolyte systems followed Arrhenius behaviour and the maximum ionic conductivity was observed for PEO:PVdF: $\mathrm{NaNO}_{3}(80: 20: 5)$ at room temperature which is attributed to the formation of the amorphous phase.
\end{abstract}

Keywords: Blend polymer electrolyte, solution cast technique, XRD, FTIR, SEM, impedance analysis, Nyquist plots. Corresponding author: asadanandachary60@gmail.com (Prof. A Sadananda Chary)

\section{Introduction}

As compared with the liquid electrolytes, the solid polymer electrolytes (SPEs) have great attention of safety and nonleakage [1]. The advantages of SPEs are having good mechanical properties, ease of fabrication as thin films, good electrochemical stability window and good electrode-electrolyte contact [2,3]. The main interest arisen in this area is due to their potential applications in electrochromic display devices, high density fuel cells, sensors and energy storage devices like batteries [4]. Basically, the choice of the polymer as a host for polymer electrolyte depends on the existence of polar (functional) groups with a large power of sufficient electron donor to form co-ordination with cations and a low hindrance to bond rotations [5]. From the economical and commercial viewpoint, PEO is the most studied polymer due to a low-cost membrane with good ionic conductivity, mechanical stability and enhanced dimensional property [6]. High dielectric constant and good ion transport exhibited by the semi-crystalline nature of PEO, which promotes an amorphous state with enabled chain segments. Particular attention has been focused on the studies of PEO based polymer electrolytes complexed with lithium salts because of their direct applications in high energy density rechargeable batteries [7]. The crystallinity of PEO must be lowered to a certain extent to promote 
better ion transmission resulting in good ionic conductivity [8]. Various approaches, such as co-polymerization, blending [9-10], plasticization [11], and inorganic nanofillers [12] have been added to enhance the ionic conductivity in the polymer electrolyte and its performance. By blending the chains of two or more polymers to form a network polymer, the electrical and structural properties can be improved. Many researchers have been exemplified the ionic conductivity of blend polymer electrolyte systems by varying polymer ratios [13-15]. The selection of polymers for blending plays a major role in attaining good mechanical, thermal and electrical properties. Mahboube Mohamadi et al [16] reported on the miscibility of PEO and PVdF blending. PVdF based SPEs are expected to have high anodic stability [17] due to the strong electron-withdrawing functional groups (-C-F). Large permittivity, comparatively low factor of dissipation and large dielectric constant is available for PVdF. To overcome the crystalline nature drawback of PEO to enhance the electrical properties, it is appropriate to blend PEO polymer with PVdF. Dhatarwal P, et al [1820] reported on electrical studies of blended polymer electrolytes based on lithium salt. Due to the limited supply of $\mathrm{Li}$ and the increasing cost of lithium with global commercialization [21], sodium has to be considered as a supplement to lithium for future energy storage applications. Sodium has high electrochemical reduction potential $\left(\mathrm{E}^{0}\left(\mathrm{Na}^{+} / \mathrm{Na}\right)=\right.$ $-2.71 \mathrm{~V})$, low cost and non-toxic nature [22-23].

In the present work, blended polymer electrolyte systems with $\mathrm{PEO}, \mathrm{PVdF}$ and $\mathrm{NaNO}_{3}$ were prepared using the solution casting technique. Since the conductivity of pure blended polymers is very low, a constant weight percentage (5\%) of $\mathrm{NaNO}_{3}$ has been added to all the samples by following (1-x) PEO : x PVdF : $5 \mathrm{NaNO}_{3}($ where $\mathrm{x}=10,20,30 \& 40 \mathrm{wt} \%)$. This work aims to examine the ionic conductivity and electrical properties based on the data obtained from impedance studies and also to study the structural properties of blended polymer electrolytes using FTIR and XRD data.

\section{Experimental Procedure}

Poly (ethylene oxide) (PEO, Mw = 2,00,000), Poly (Vinylidene Fluoride) (PVDF, Mw = 2,70,000) and sodium nitrate $\left(\mathrm{NaNO}_{3}, \mathrm{Mw}=84.99\right)$ were purchased from Sigma Aldrich, India. Dimethyl Formamide (DMF, AR grade) was purchased from Merck. Solid blend polymer electrolyte systems have been prepared by varying PEO and PVDF weight percentages with constant $5 \mathrm{wt} \%$ of $\mathrm{NaNO}_{3}$ by solution cast technique. $\mathrm{PEO}, \mathrm{PVdF}$ and $\mathrm{NaNO}_{3}$ were dissolved in $50 \mathrm{ml}$ of DMF on a magnetic stirrer by maintaining an hour gap for each chemical dissolution. The complete solution has been heated at $40^{\circ} \mathrm{C}$ for 2 hours. Again, the stirring was continued for 24 hours to get the homogeneous solution. The obtained homogeneous solution has been cast on a petri dish and dried in an oven at $50^{\circ} \mathrm{C}$ for 36 hours. The SPE films were prepared in accordance with (1-x) PEO: xPVDF: $5 \mathrm{NaNO}_{3}$ (where $\mathrm{x}=10,20,30$, and $40 \mathrm{wt} \%$ ). The prepared samples were labeled as shown in table.1 and stored in desiccators. The samples were investigated to study the structural and electrical properties after seven days.

\section{Results and Discussions}

3.1 X-Ray Diffraction studies: Fig. 1 shows the X-Ray diffraction patterns of PEO, $\mathrm{PVdF}, \mathrm{NaNO}_{3}$ (pure forms) and polymer blend complexed with $\mathrm{NaNO}_{3}$. The characteristic peaks of pure $\mathrm{NaNO}_{3}\left(29.11^{\circ}\right)$ and PEO $\left(19.08^{0}, 23.52^{0}\right)$ signify the crystalline form of these two materials. The $\beta$ and $\alpha$ phase peaks of $\mathrm{PVdF}$ were observed at $20.2^{0}$ and $38.8^{0}$ 
respectively in accordance with earlier results [24]. It has been observed that the intensities of blend polymer electrolyte complexed with $\mathrm{NaNO} 3$, the intensities were less as compared with pure forms of PEO, PVdF and NaNO3. Peaks corresponding to pure PEO are also present in the complex polymer blend. This indicates the simultaneous presence of both crystalline complexed and uncomplexed PEO. It is also found that no $\mathrm{NaNO}_{3}$ related peaks were observed in complexed blend polymer, which means that there is no excessive salt in the complexed polymer films [25]. Crystalline size has been calculated using Sherrer's equation and shown in table 1. From the figure, it has been observed that the peak broadening increased and intensity decreased by loading PVdF polymer concentration. It is also noticed that the peak broadening decreased and intensity has been increased from $70 \% \mathrm{PVdF}$, which directly indicates the change in the crystalline nature of the films. This confirms the complexation of blend polymer with salt and the most significant change was observed for PPN-80 complexed blend polymer electrolyte.

\subsection{FT-IR analysis}

The FTIR studies of pure PEO, PVDF, $\mathrm{NaNO}_{3}$ and the blend polymer electrolyte systems (PEO:PVDF: $\mathrm{NaNO}_{3} / 90: 10: 5$, 80:20:5, 70:30:5 and 60:40:5) are depicted in fig. 2. The FTIR spectroscopic analysis shows the evidence of the complexity between the various components in the SPE systems. The $\alpha, \beta$ and $\gamma$ phases were observed at $1383 \mathrm{~cm}^{-1}, 840 \mathrm{~cm}^{-1}$ and $510 \mathrm{~cm}^{-1}$ respectively match with earlier studies [26] in intrinsic PVdF. The peaks at 1263 and $1160 \mathrm{~cm}^{-1}$ in the complex are assigned to the stretching frequencies of $\mathrm{C}-\mathrm{F}$ and $\mathrm{CF}_{2}$ respectively of PVDF. The peaks at $1100 \mathrm{~cm}^{-1}$ and $1074 \mathrm{~cm}^{-1}$ correspond to the $\mathrm{C}-\mathrm{O}-\mathrm{C}$ stretching mode(strong) of PEO. It is found that the peak at $1750 \mathrm{~cm}^{-1}$ corresponds to $\mathrm{C}=\mathrm{O}$ stretching mode of $\mathrm{PEO}$ [27]. $\mathrm{C}-\mathrm{H}$ stretching vibration mode was observed at $2880 \mathrm{~cm}^{-1}$. It is noticed that all the phases of PVDF disappeared except $\alpha$ (at $1383 \mathrm{~cm}^{-1}$ ) in blended electrolyte systems, which denotes the crystalline region of the PEO. The broadband centered around $3450 \mathrm{~cm}^{-1}$ of the O-H stretch also appeared and increased with the loading of PVDF. And, the peak around $2920 \mathrm{~cm}^{-1}$ was observed which is $\mathrm{C}-\mathrm{H}$ stretching vibrational band in blend polymer electrolyte systems.

\subsection{SEM Analysis}

The SEM images of pure PEO, PVDF, $\mathrm{NaNO}_{3}$, PEO:PVdF(80:20) blended film and PEO:PVDF: $\mathrm{NaNO}_{3}$ (PPN90,PPN-80) complexed polymer blend electrolyte films are shown in fig.3.The image in fig. 3a shows a rough morphology with a great deal of micropores which confirms the semicrystalline phase of PEO [28] and fig.3b shows the formation of a large number of micro-crystallites in pure PVDF. The highly crystalline phase of NaNO3 can be seen from fig.3c. Fig.3d shows that there is no apparent interface between two polymers which clearly indicates that PEO and PVDF have good compatibility. The microstructure of pure PEO, $\mathrm{NaNO}_{3}$ and PEO:PVDF blend system shows a rough surface, which indicates that the crystalline nature is dominating over amorphous nature [29-30]. Figs. $3 \mathrm{e}, 3 \mathrm{f} \& 3 \mathrm{~g}$ show the images of the salt complexed blended films. It is observed that the amorphous nature increased at the expense of crystallinity by increasing the PVDF content. By comparing figs. 3e, $3 \mathrm{f} \& 3 \mathrm{~g}$, PPN-80 shows more smoothness as compare with PPN-90 and PPN-70.

\subsection{Impedance Spectroscopic Analysis}


Fig. 4 shows the Nyquist plots for the polymer blend electrolyte system with different blend compositions and a fixed concentration of salt $\mathrm{NaNO}_{3}$ (i.e. (1-x) $\mathrm{PEO}+\mathrm{x} \mathrm{PVDF}+5 \mathrm{NaNO}_{3}$ ) at room temperature. A semicircle in the highfrequency region and spikes with an angle less than $90^{\circ}$ in the low-frequency region were observed for all the samples at room temperature, which indicates that the sample is partially capacitive and resistive. The ionic conductivity of the polymer blend electrolyte system was determined from complex impedance studies. The intercept of the semicircle on the $\mathrm{X}$-axis gives the bulk resistance $\left(\mathrm{R}_{\mathrm{b}}\right)$ of the sample. From Fig.4(a), it can be observed that the sample PPN-80 has the lowest bulk resistance. Hence, it possesses the highest ionic conductivity at room temperature. Fig.4(b) shows the Nyquist plots for PPN-80, which exhibited the highest ionic conductivity showing similar behavior with increasing temperature from $298 \mathrm{~K}$ to $338 \mathrm{~K}$.

\subsection{AC Conductivity}

The effect of blend composition on the frequency-dependent conductivity (AC conductivity) between the temperatures $298 \mathrm{~K}$ and $338 \mathrm{~K}$ was studied. Fig.5(a) shows the variation of electrical conductivity with the frequency of various prepared samples at room temperature. From the figure, it can be observed that PPN-80 sample has the highest conductivity.In general, the frequency-dependent conductivity could exhibit three types of dispersion regions with frequency, (i) low-frequency region, which demonstrates the space charge polarization, (ii) dc saturation zone in midfrequency region and (iii) dc-to-ac switching at high frequency-zone, which is due to the coulombic interaction of charge carrier and disruption within the framework [31,32]. The change in conductivity with frequency in the highfrequency band is demonstrated by the well-known Jonscher AC power law given by the following expression.

$$
\sigma^{\prime}(\omega)=\sigma_{0}+A \omega^{\mathrm{n}}
$$

here $\sigma^{\prime}(\omega)$ is the conductivity at a particular frequency, $\sigma_{0}$ is the conductivity at low frequencies and is independent of frequency and known as DC conductivity, A is a constant, and $n$ is the frequency-exponent. Fig. 5(b) shows the variation of electrical conductivity with the frequency of PPN-80 sample between the temperatures $298 \mathrm{~K}$ and $338 \mathrm{~K}$, which is similar to other electrolyte materials previously analyzed and exhibit all the characteristic dispersion regions. [33-35].

\subsection{Ionic Conductivity}

Fig. 6 shows the variation of ionic conductivity versus reciprocal temperature in the range 298-338K for polymer blend electrolyte systems. The ionic conductivities have been calculated using the relation $\sigma=\frac{t}{\mathrm{AR}_{\mathrm{b}}}$, where $\mathrm{t}$ is the thickness and A is the area of the sample [36-37]. The calculated ionic conductivities have been listed in Table.1. It is observed that as the concentration of PVDF increases, the ionic conductivity increases. The maximum conductivity obtained for PPN-80 system at $298 \mathrm{~K}$ is $9.334 \times 10^{-5} \mathrm{~S} / \mathrm{cm}$ which indicates decreased crystallinity and increased amorphous phase. Further increase in the concentration of PVDF (PPN-70, PPN-60) the conductivity decreased. A larger PVDF ratio in electrolytes results in higher viscosity, which in return reduces the mobility of the charge carriers and thus lowers the conductivity [38].

\subsection{Dielectric and Tangent loss Analysis}

The complex dielectric permittivity $\left(\varepsilon^{*}\right)$ of a material as frequency dependence is given as, $\varepsilon^{*}=\varepsilon^{\prime}(\omega)+\mathrm{j} \varepsilon^{\prime \prime}(\omega)$ 
Fig. 7 represents the complex dielectric permittivity of all blend polymer electrolyte systems and the temperature dependence of dielectric permittivity of PPN-80 sample. It can be noticed from fig. 7(a). That the shape of $\varepsilon^{\prime}$ with frequency is similar for all the samples and a huge increase in $\varepsilon^{\prime}$ is observed for PPN-80 at $10^{2} \mathrm{~Hz}$ compared to other samples. At intermediate frequency $\left(10^{2}-10^{3} \mathrm{~Hz}\right)$, there is a decrease in permittivity and all the permittivity values have become saturated above $10^{3} \mathrm{~Hz}$. The high dielectric permittivity at low frequency is attributed to the superiority of electrode polarization, where, the inclination of the dipoles to orient themselves in the direction of the field applied is more [39-40]. The decline in permittivity with frequency in the intermediate zone is partly related to the involvement of the interfacial polarization effect, where, the dipoles cannot align themselves in the direction of the field employed. The change in permittivity values in different polymer electrolyte systems confirms the impact of polymer ratios on electrode polarization. Increases of PVdF enables to disperse the ions more and reached to a maximum for PPN-80. The dipole mobilization depends on the material's ductility. At higher temperatures, the dipoles can align easily whereas extremely crosslinked material can cause orientation difficulties. Fig 7(b) depicts the permittivity variation of PPN-80 sample at different temperatures. It is obvious that with increasing frequency, the permittivity decreases monotonically and, displays a plateau in the high-frequency zone after a cross-over point [41]. The increase in dielectric constant at low frequency with temperature is attributable to space charge and electrode polarization impacts which are responsible for the non-Debye action [42].

Fig. 8(a) represents the dielectric loss of different blend polymer electrolyte systems with frequency. It can be noticed from the figure that the dielectric loss is maximum at the lower frequency (at $100 \mathrm{~Hz}$ ) and gradually decreased with an increase in frequency and these values have become saturated at the higher frequency. In the low-frequency region, the rise in dielectric loss can be explained by the polarization effect at the electrode/electrolyte interface and free flow of charges in the system and also there will be ample time for the charges to be formed at the interface before the electric field has been altered, which has led to high apparent value of $\varepsilon^{\prime \prime}$.

In the high-frequency region, there was no time to accumulate the charges at the interface [44-45]. It can also be noticed that as the polymer ratio changed, the dielectric loss also changed and the maximum dielectric loss has been observed for PPN-80 sample. It can be seen from fig. 8(b) that $\varepsilon^{\prime \prime}$ has been raised with temperature due to an increase in the movement of free ions. However, the rise in temperature increases the degree of ion-pair dissociation mechanism and acknowledges the rise in the concentration of free carriers at the interface [46].

The variation of loss tangent $(\tan \delta)$ with the logarithmic frequency of blend polymer electrolyte systems have been shown in fig. 9(a). The loss spectrum of all samples showed a broad peak at a characteristic frequency which confirms the existence of relaxing dipoles in all the systems. It is noted that the maximum peak shifted towards the highfrequency region by varying the polymer ratio and the maximum shift has been observed for PPN-80. The shift towards the high-frequency region suggested the fast-segmental motion coupled with the mobile ions which reduces the relaxation times [47]. The sharp peak intensity of the loss tangent increases with an increase in temperature as shown for PPN-80 in fig. 9(b) which indicates that the charge carriers are thermally activated [48].

\subsection{Complex Electric Modulus Analysis}


The complex electric modulus, $\mathrm{M}^{*}=\mathrm{M}^{\prime}(\omega)+\mathrm{jM}^{\prime \prime}(\omega)$, where $\mathrm{M}^{\prime}$ and $\mathrm{M}^{\prime \prime}$ are the real and imaginary elements of electric modulus. The following equations can be used to obtain $\mathrm{M}^{\prime}$ and $\mathrm{M}^{\prime \prime}$.

$M^{\prime}(\omega)=\frac{\varepsilon^{\prime}}{{\varepsilon^{\prime}}^{2}+\varepsilon^{\prime \prime}} \quad$ and $\quad M^{\prime \prime}(\omega)=\frac{\varepsilon^{\prime \prime}}{\varepsilon^{\prime 2}+\varepsilon^{\prime \prime 2}}$

Where $\varepsilon^{\prime}$ and $\varepsilon^{\prime \prime}$ are the real and imaginary parts of dielectric constants. Fig.10 depicts the variation of real modulus $\left(\mathrm{M}^{\prime}\right)$ and imaginary modulus $\left(\mathrm{M}^{\prime \prime}\right)$ with the frequency of PPN-90,80,70 \& 60 blend polymers at room temperature (298K) and PPN-80 sample at various temperatures. The complex electric modulus formalism has been introduced because it can distinguish between electrode polarization and other interface impacts. Dielectric representations are generally known to illustrate the bulk dielectric behavior and remove the interface impact. Modulus spectroscopy graphs are notably important in distinguishing materials with identical resistances but distinct capacitances from the spectral components. The other benefit of the electric modulus formalism is that it eliminates the electrode impact. Complex electric modulus methodology has been selected for the aforementioned causes. [49]. In fig.10a \& 10b, $\mathrm{M}^{\prime}$ approaches 0 , confirming the existence of noticeable electrode and/or ionic polarization in the ambient temperature at lower frequencies. A long-tail found at low frequencies is due to the high capacitance related to the electrodes. [50] From fig. 10c \&10d, the $\mathrm{M}^{\prime \prime}$ spectrum shows an asymmetric spike roughly centered in the region of dispersion. These logarithmic scale spectra indicate that the low-frequency band in which the values of $\mathrm{M}^{\prime}$ and $\mathrm{M}^{\prime \prime}$ are about zero reflects the area occupied by the EP, whereas the sharp rise in the region of the high-frequency zone is due to the bulk properties of the electrolytes.

\section{Conclusons}

PEO and PVdF based blend polymer electrolytes with $5 \mathrm{wt} \%$ of $\mathrm{NaNO}_{3}$ were prepared by solution cast method by varying the polymers wt $\%$ ratio. The effect of polymer ratio variation on morphology, structural and electrical studies investigated systematically. By loading the PVdF, the solid polymer electrolyte exhibits improved electrical properties. In specific, $80 \mathrm{wt} \%$ PEO: $20 \mathrm{wt} \% \mathrm{PVdF}$ with $5 \mathrm{wt} \%$ of $\mathrm{NaNO}_{3}$ has uniform surface and highly amorphous compared with other samples, which has been proven in XRD, SEM and FT-IR analysis. A large plateau region in frequency-dependent conductivity suggests that conductivity is mostly due to ions migration and the sudden rise of ionic conductivity in the high-frequency region is due to the hopping mechanism. Analysis of electric modulus reveals the distribution of relaxation time. Dielectric studies reveal that energy storage $\left(\varepsilon^{\prime}\right)$ at the low-frequency area is higher because of polarization and higher value of energy loss $\left(\varepsilon^{\prime \prime}\right)$ is due to non-Debye type relaxation.

\section{Compliance with ethical standards}

Conflict of interest: The authors declare that they have no conflict of interest.

\section{References}

1. T. Itoh, Y. Mitsuda, T. Ebina, T. Uno, M. Kubo, Solid polymer electrolytes composed of polyanionic lithium salts and polyethers. J. Power Sources 189: 531-535 (2009)

2. S.B. Aziz, Z.H.Z. Abidin, Innovative method to avoid the reduction of silver ions to silver nanoparticles (Agp/Ago ) in silver ion conducting based polymer electrolytes. Phys. Scripta 90: 035808 (2015) 
3. L. Zang, J. Luo, J. Guo, H. Liu, J. Ru, Preparation and characterization of poly(ethylene glycol)/organovermiculite nanocomposite polymer electrolytes. Polym. Bull. 65: 669-680 (2010)

4. M. Hema, S. Selvasekarapandian, G. Hirankumar, A. Sakunthala, D. Arunkumar, H. Nithya, Structural and thermal studies of PVA: NH4I. J. Phys. Chem. Solid. 70: 1098-1103 (2009)

5. S.B. Aziz, $\mathrm{Li}^{+}$ion conduction mechanism in poly(e-caprolactone)-based polymer electrolyte. Iran. Polym. J. 22: 877-883 (2013)

6. M.M. Borgohain, T. Joykumar, S.V. Bhat, Studies on a nanocomposite solid polymer electrolyte with hydrotalcite as filler. Solid State Ionics 181: 964-970 (2010)

7. E.M. Fahmi, A. Ahmad, N.N.M. Nazeri, H. Hamzah, H. Razali, M.Y.A. Rahman, Effect of $\mathrm{LiBF}_{4}$ salt concentration on the properties of Poly(ethylene oxide)-based composite polymer electrolyte. Int. J. Electrochem. Sci. 7:5798-5804 (2018)

8. Z. Xue, D. He, X. Xie, Poly(ethylene oxide)-based electrolytes for lithiumion batteries. J Mater Chem A 3:19218-19253 (2015)

9. CH.V.S. Reddy, Z. Quan-Yao, M. Li-Qiang, et al, Electrochemical studies on PVC/PVdF blend-based polymer electrolytes. J Solid State Electrochem 11:543-548 (2007)

10. S.K. Tripathi, A. Gupta, M. Kumari, Studies on electrical conductivity and dielectric behaviour of PVdFHFP-PMMA-NaI polymer blend electrolyte. Bull Mater Sci 35:969-975 (2012)

11. S. Rajendran, M. Sivakumar, R. Subadevi, Investigations on the effect of various plasticizers in PVA-PMMA solid polymer. Mater Lett 58:641-649 (2004)

12. M. Sundar, S. Selladurai, Effect of Fillers on Magnesium- Poly(Ethylene Oxide). Solid Polymer Electrolyte. Ionics 12:281- 286 (2006)

13. S.Amudha, S.A. Sunthathiraraj, P. Marimuthu, Performance characteristic of pyrazole as an effective dopant in a blended polymer electrolyte for nanocrystalline dye sensitized solar cell application. Chem Sci Trans 2:141-146 (2013)

14. R. Natarajan, S. Subramanian, P. Moni, et al, Lithium ion conducting solid polymer blend electrolyte based on bio-degradable polymers. Bull Mater Sci 36:333-339 (2013)

15. K. Sundaramahalingam, M. Muthuvinayagam, N. Nallamuthu, AC Impedance Analysis of Lithium Ion Based PEO:PVP Solid Polymer Blend Electrolytes. Polym. Sci. Ser. A 61: 565-576 (2019)

16. M. Mohamadi, H. Garmabi, M. Papila, Effect of Miscibility State on Crystallization Behavior and Polymorphism in Crystalline/ Crystalline Blends of Poly(vinylidene fluoride)/Poly(ethylene oxide), Macromolecular Research, 24: 698-709 (2016)

17. H.S. Choe, J. Giaccai, M. Alamgir and K.M. Abraham, Preparation and characterization of poly(vinyl sulfone)- and poly(vinylidene fluoride)-based electrolytes, Elecrochimica Acta 40: 2289-2293 (1995)

18. P. Dhatarwal, R.J. Sengwa, Dielectric polarization and relaxation processes of the lithium-ion conducting PEO/PVDF blend matrix-based electrolytes: effect of $\mathrm{TiO}_{2}$ nanofiller. SN Appl Sci 2: 833 (2020) 
19. R.J. Sengwa, D. Priyanka, C. Shobhna, Study of time-ageing effect on the ionic conduction and structural dynamics in solid polymer electrolytes by dielectric relaxation spectroscopy. Solid State Ionics 324:247-259 (2018)

20. P. Dhatarwal, R.J. Sengwa, Polymers compositional ratio dependent morphology, crystallinity, dielectric dispersion, structural dynamics, and electrical Conductivity of PVDF/PEO blend films. Macromol Res 27:1009-1023 (2019)

21. S. Guo, H. Yu, P. Liu, Y. Ren, T. Zhang, et al, High-performance symmetric sodium-ion batteries using a new bipolar material $\mathrm{O}_{3}$ - type $\mathrm{Na}_{0.8} \mathrm{Ni}_{0.4} \mathrm{Ti}_{0.6} \mathrm{O}_{2}$. Energy Environ Sci 00:1-3 (2014)

22. V. Palomares, M. Casas-Cabanas, E. Castillo-Martinez, et al, Update on Na based battery materials. A growingresearch path. Energy Environ Sci 6:2312-2337 (2013)

23. D. Kundu, E. Talaie, V. Duffort, L.F. Nazar, The emerging chemistry of sodium ion batteries for electrochemical energy storage. Angew Chem Int 54: 3431-3448 (2015)

24. M.H. Sankar, Ravikant, K. Ashok, et al, Dielectric/ferroelectric properties of ferroelectric ceramic dispersed poly (vinylidene fluoride) with enhanced $\beta$-phase formation. Mater. Chemistry Phys 230: 221-230 (2019)

25. T. Sreekanth, M.J. Reddy, S. Ramalingaiah, U.V.S. Rao, Ion-conducting polymer electrolyte based on poly(ethylene oxide) complexed with $\mathrm{NaNO}_{3}$ salt-application as an electrochemical cell. Journal of power sources 79: 105-110 (1999)

26. X. Cai, T. Lei, D. Sun, L. Lin, A critical analysis of the a, b and $\mathrm{g}$ phases in poly(vinylidene fluoride) using FTIR. RSC Advances 7: 15382-15389 (2017)

27. S. Choudhary, R.J. Sengwa, Effects of different inorganic nanoparticles on the structural, dielectric and ion transportation properties of polymers blend based nanocomposite solid polymer electrolytes, Electrochimica Acta, 247: 924-941 (2017)

28. J. Xi, X. Qiu, M. Cui, X. Tang, W. Zhu, L. Chen (2005) Enhanced electrochemical properties of PEO-based composite polymer electrolyte with shape-selective molecular sieves Journal of Power Sources 156: 581$588(2005)$

29. Y. Wang, Y. Pan, L. Wang, Conductivity studies of plasticized PEO-lithium chlorate-FIC filler composite polymer electrolytes. Materials Letters 59: 3021-3026 (2005)

30. B. Jinisha B, K.M. Anilkumar, M. Manoj, V.S. Pradeep, S. Jayalekshmi, Development of a novel type of solid polymer electrolyte for solid state lithium battery applications based on lithium enriched poly (ethylene oxide) (PEO)/poly (vinyl pyrrolidone) (PVP) blend polymer. Electrochim Acta 235: 210-222 (2017)

31. A. Arya, A.L. Sharma, Tailoring of the structural, morphological, electrochemical, and dielectric properties of solid polymer electrolyte. Ionics 25: 1617-1632 (2019)

32. R. Manjuladevi, M. Thamilselvan, S. Selvasekarapandian, et al, Mg-ion conducting blend polymer electrolyte based on poly(vinyl alcohol)- poly (acrylonitrile) with magnesium perchlorate. Solid State Ionics 308: 90-100 (2017) 
33. S. Choudhary, R.J. Sengwa, Effects of different inorganic nanoparticles on the structural, dielectric and ion transportation propertyes of polymers blend based nanocomposite solid polymer electrolytes. Electrochim Acta 247:924-941 (2017)

34. J.R. Macdonald, W.B. Johnson, Impedance Spectroscopy: Theory, Experiment, and Applications. John Wiley \& Sons, Hoboken, New Jersey. (2005)

35. S.B. Aziz, T.J. Woo, M.F.Z. Kadir, H.M. Ahmed, A conceptual review on polymer electrolytes and ion transport models. J Science: Advanced Mater Devices 3:1-17 (2018)

36. A. Arya, A.L. Sharma, Effect of salt concentration on dielectric properties of Li-ion conducting blend polymer electrolytes. J Mater Sci 29: 17903-17920 (2018)

37. P. Pal, A. Ghosh, Influence of $\mathrm{TiO}_{2}$ nano-particles on charge carrier transport and cell performance of PMMA-LiClO 4 based nano-composite electrolytes. Electrochim Acta 260: 157-167 (2018)

38. Z. Jiang, B. Carroll, K.M. Abraham, Studies of some poly(vinylidene fluoride) electrolytes. Electrochim. Acta 42: 2667-2677 (1997)

39. N.L. Singh, S. Shah, A. Qureshi, A. Tripathi, F. Singh, D.K. Avasthi, P.M. Raole, Effect of ion beam irradiation on metal particle doped polymer composites. Bull Mater Sci 34: 81-88 (2011)

40. S. Ramesh, G.P. Ang, Impedance and FTIR studies on plasticized PMMA- $\mathrm{LiN}\left(\mathrm{CF}_{3} \mathrm{SO}_{2}\right)_{2}$ nanocomposite polymer electrolytes. Ionics 16: 465-473 (2010)

41. P. Sharma, D.K. Kanchan, Effect of nanofiller concentration on conductivity and dielectric properties of poly(ethylene oxide)-poly(methyl methacrylate) polymer electrolytes. polym Int 63(2): 290-295 (2013)

42. H.M. Zaki, AC conductivity and frequency dependence of the dielectric properties for copper doped magnetite. Physica B Condensed Matter 363: 232-244 (2005)

43. H. Nithya, S.S.Selvasekarapandian, D.A. Kumar et al, Thermal and dielectric studies of polymer electrolyte based on P(ECH-EO). Mater Chem Phys 126: 404-408 (2011)

44. M.L. Verma, H.D. Sahu, Ionic conductivity and dielectric behavior of PEO-based silver ion conducting nanocomposite polymer electrolytes. Ionics 21: 3223-3231 (2015)

45. S. Jayanthi, B. Sundaresan, Effect of ultrasonic irradiation and $\mathrm{TiO}_{2}$ on the determination of electrical and dielectric properties of $\mathrm{PEO}-\mathrm{P}(\mathrm{VdF}-\mathrm{HFP})-\mathrm{LiClO}_{4}$-based nanocomposite polymer blend electrolytes. Ionics 21 : $705-717$ (2014)

46. K.K. Ganta, V.R. Jeedi, K.V. Kumar, E.L. Narsaiah, Effect of $\mathrm{NaClO}_{4}$ on the ionic conductivity and dielectric properties of sodium ion-conducting PEO/PVDF solid polymer electrolytes for energy storage applications. Journal of Green Engineering 10: 5589-5606 (2020)

47. S. Ibrahim, S. M. M. Yasin, N.M. Nee, R.Ahmad, M.R. Johan, Conductivity and dielectric behaviourof PEObased solid nanocomposite polymer electrolytes. Solid State Communications 152 : 426-434 (2012)

48. S. Saha, T.P. Sinha, Low-temperature scaling behavior of $\mathrm{BaFe}_{0.5} \mathrm{Nb}_{0.5} \mathrm{O}_{3}$. Phys $\operatorname{Rev} \mathrm{B}$ 65: 134103 (2002)

49. S. Ramesh, A.K. Arof, Ionic conductivity studies of plasticized poly(vinyl chloride) polymer electrolytes. Mater Sci Eng B 85: 11-15 (2001) 
50. R.S. Hafez, N.A. Hakeem, A.A. Ward, A.M. Ismail, F.H. Abd El kader, Dielectric and Thermal Properties of PEO/PVDF Blend Doped with Different Concentrations of $\mathrm{Li}_{4} \mathrm{Ti}_{5} \mathrm{O}_{12}$ NanoparticlesJ Inorg Organomet Polym Mater. 30: 4468-4480 (2020) 
Figures

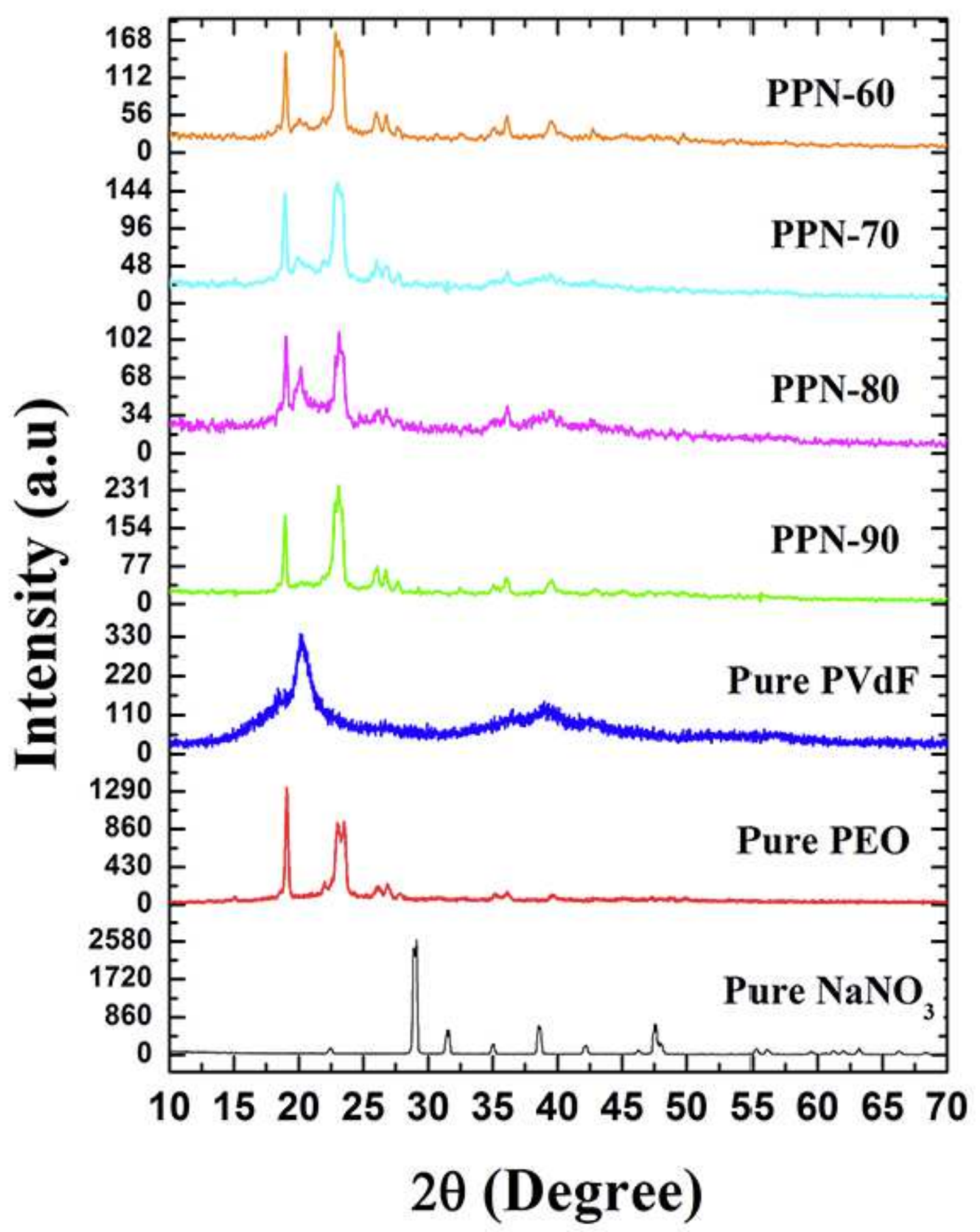

Figure 1

XRD Patterns of Pure PEO, PVdF, NaNO3, PPN-90, PPN-80, PPN-70 and PPN-60. 


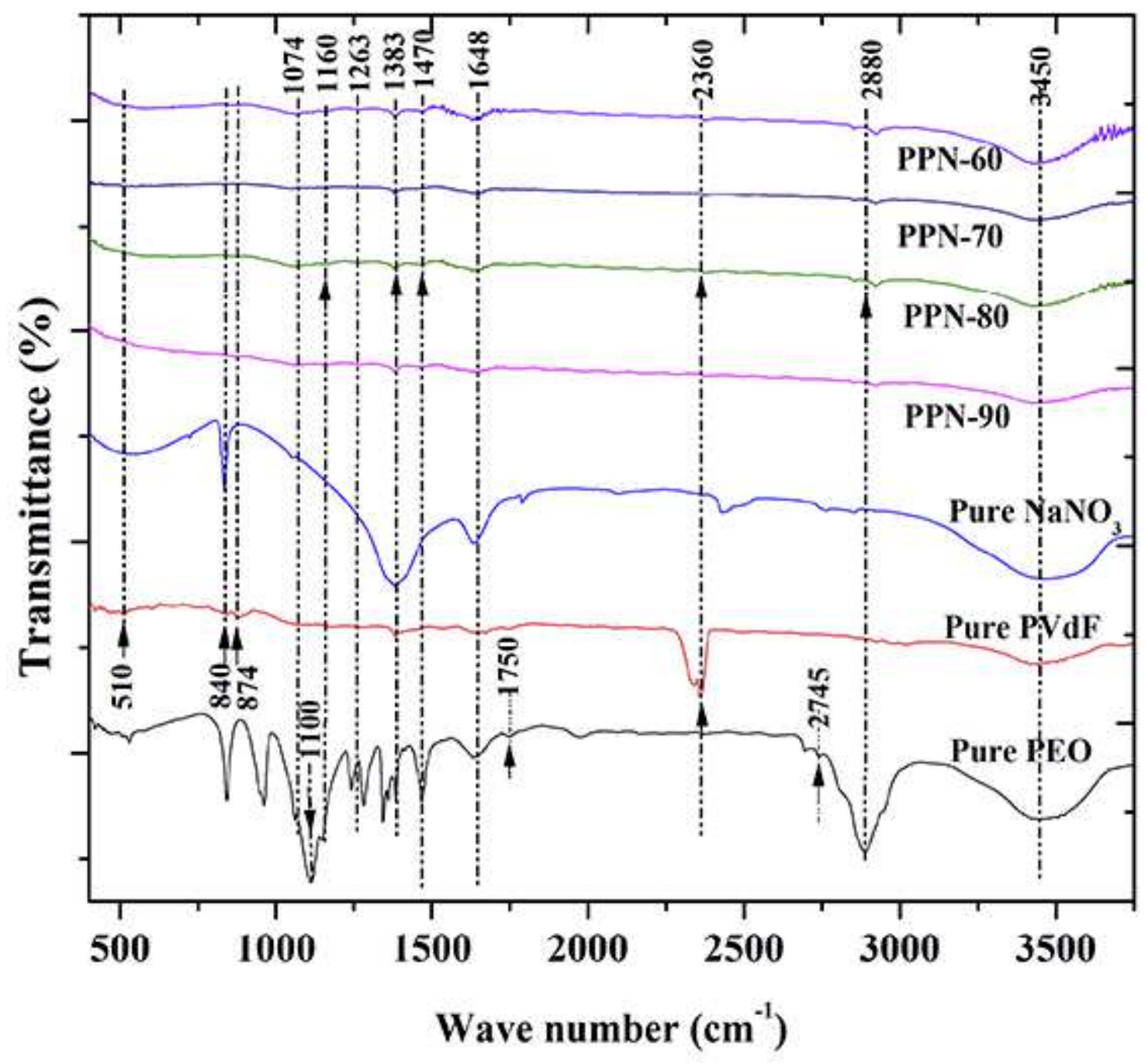

Figure 2

FT-IR Analysis of Pure PEO, PVdF, NaNO3, PPN-90, PPN-80, PPN-70 and PPN-60. 

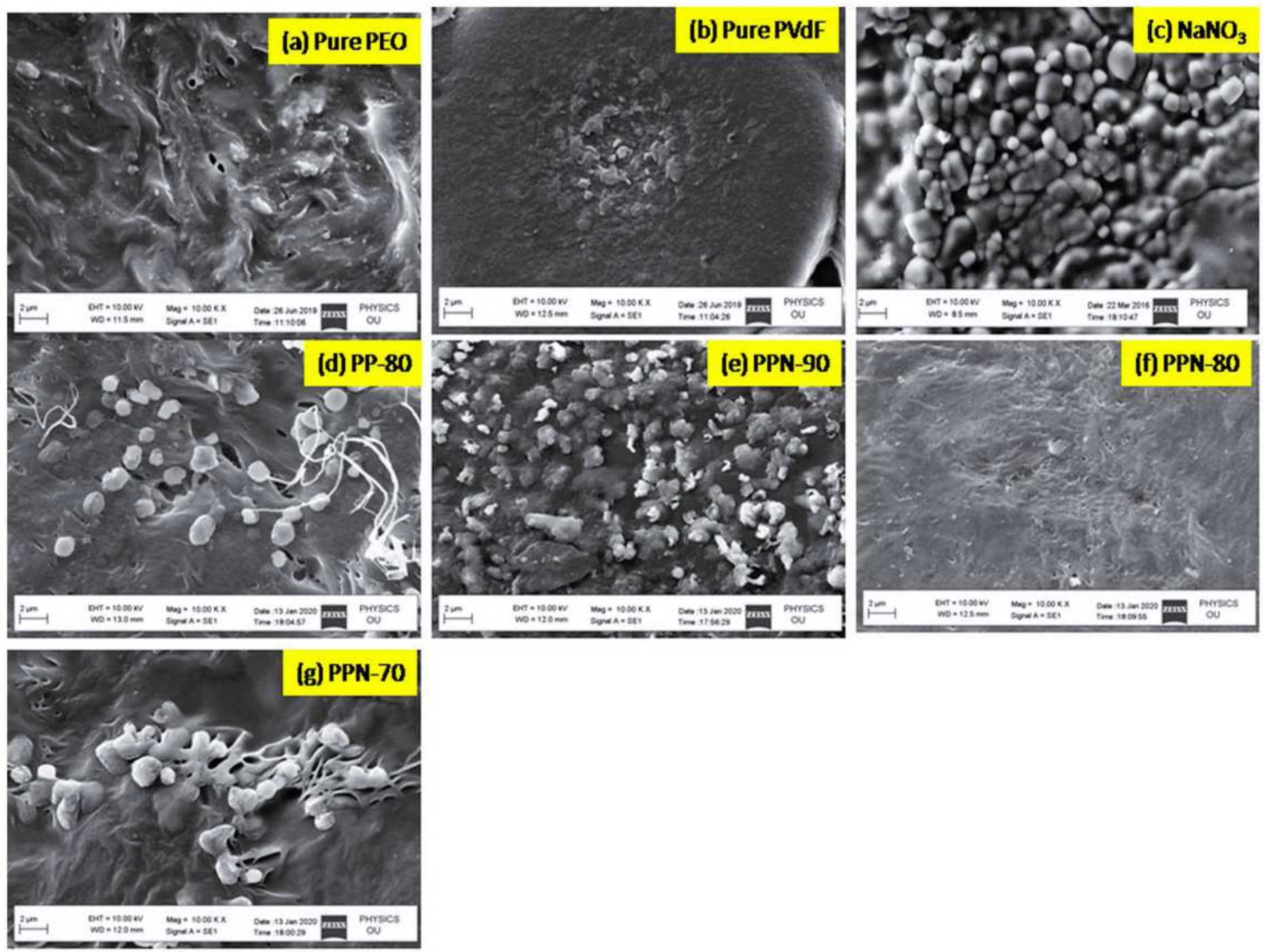

Figure 3

SEM morphological images of (a) Pure PEO, (b) Pure PVdF, (c) Pure NaNO3, (d) Pure PP(PEO 80 : PVdF 20), (e) PPN-90, (f) PPN-80, (g) PPN-70.
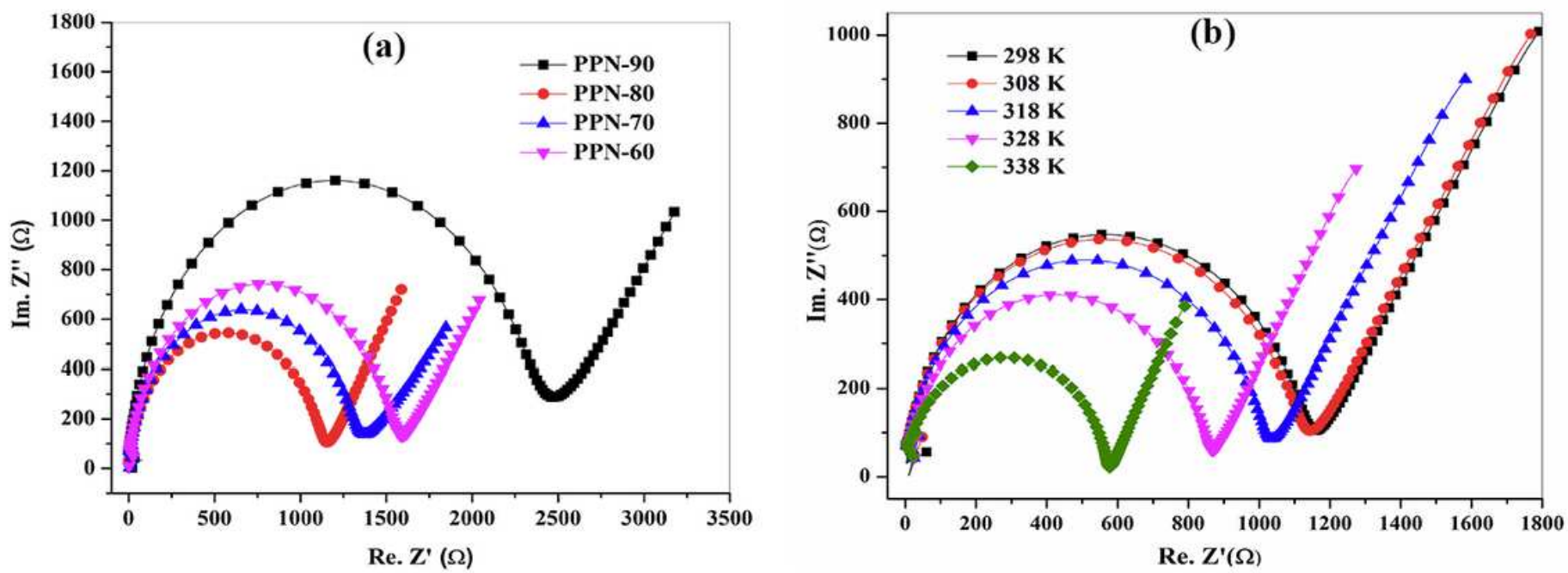
Figure 4

(a). Cole-Cole plots of PPN-90, PPN-80, PPN-70 and PPN-60 at 298K (b) .Complex Impedance plots of $\mathrm{PPN}-80$ at various temperatures
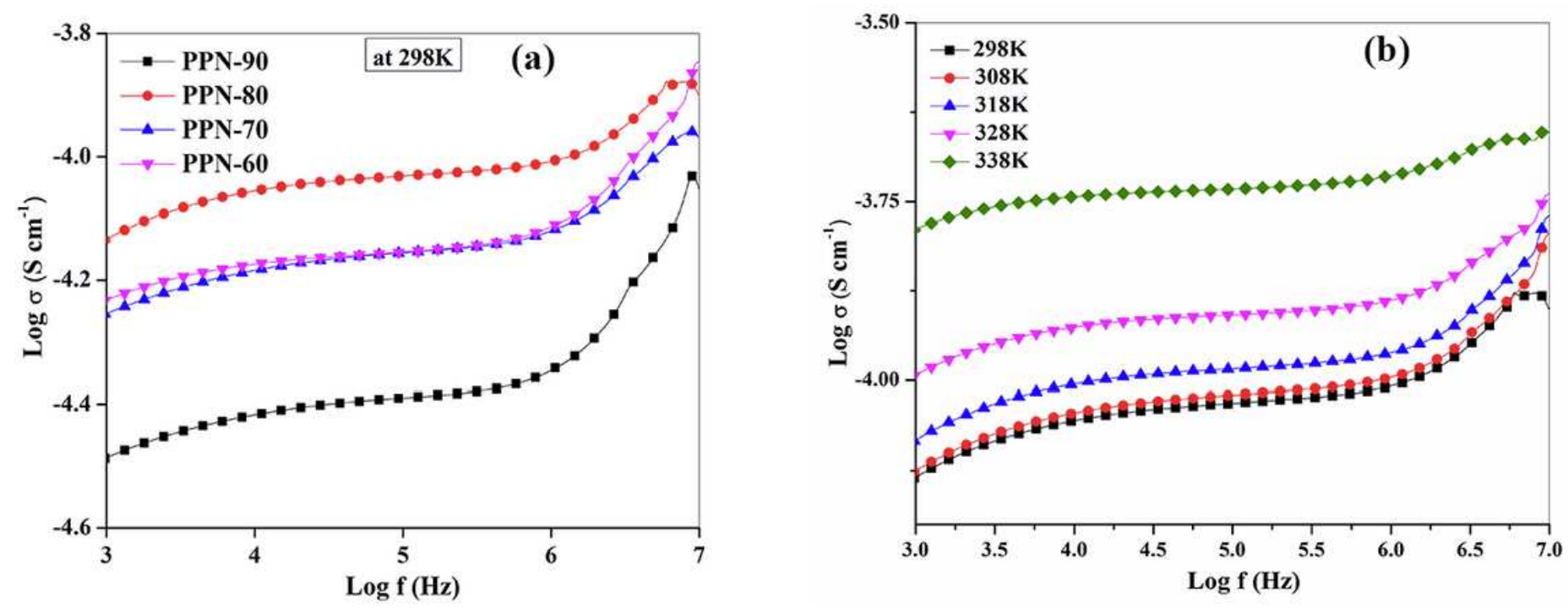

Figure 5

(a). Frequency dependent conductivity of PPN-90, PPN-80, PPN-70 and PPN-60 (b). at different temperatures of PPN-80. 


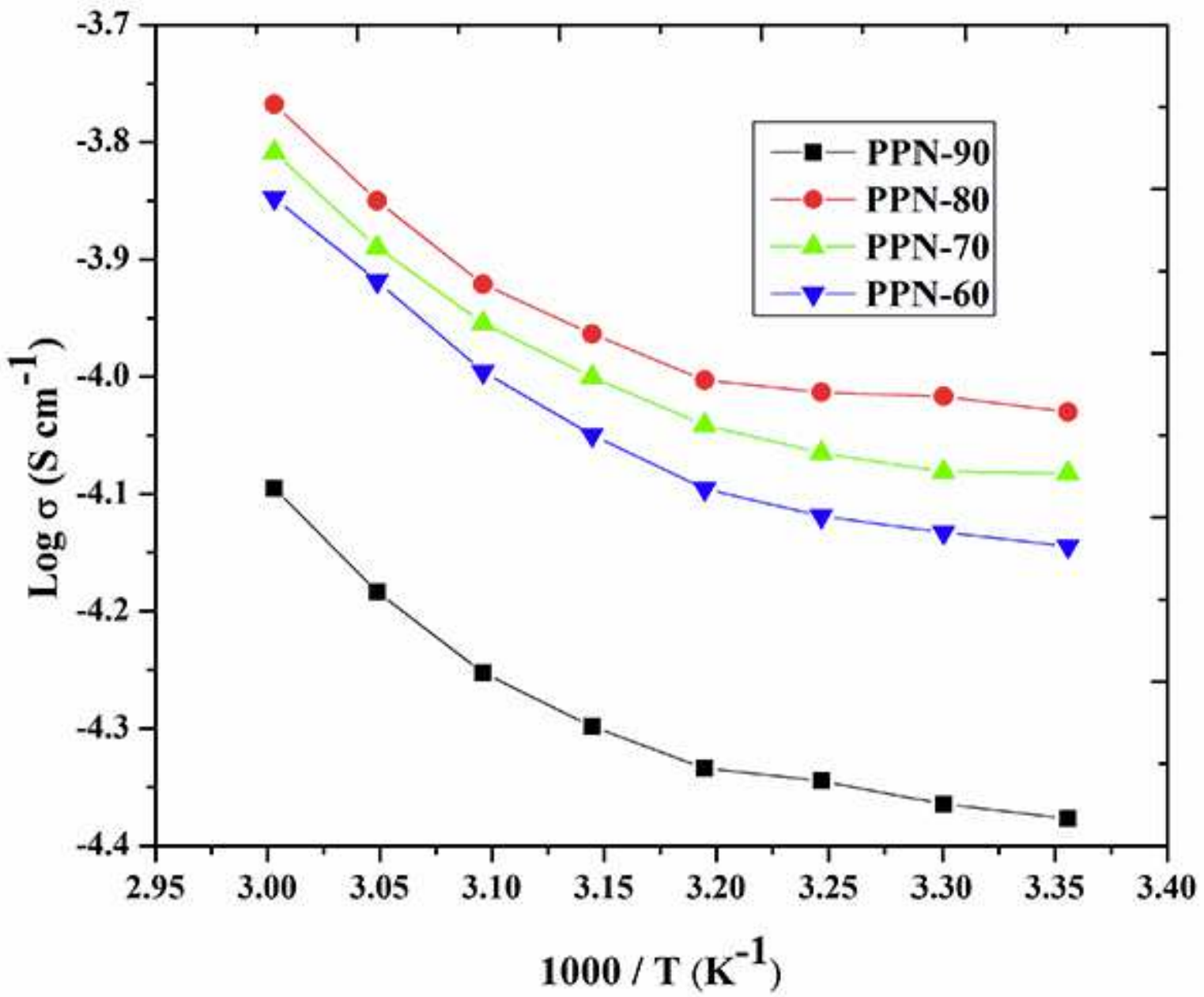

Figure 6

Arrhenius plot: Log $\otimes$ Vs. 1000/T
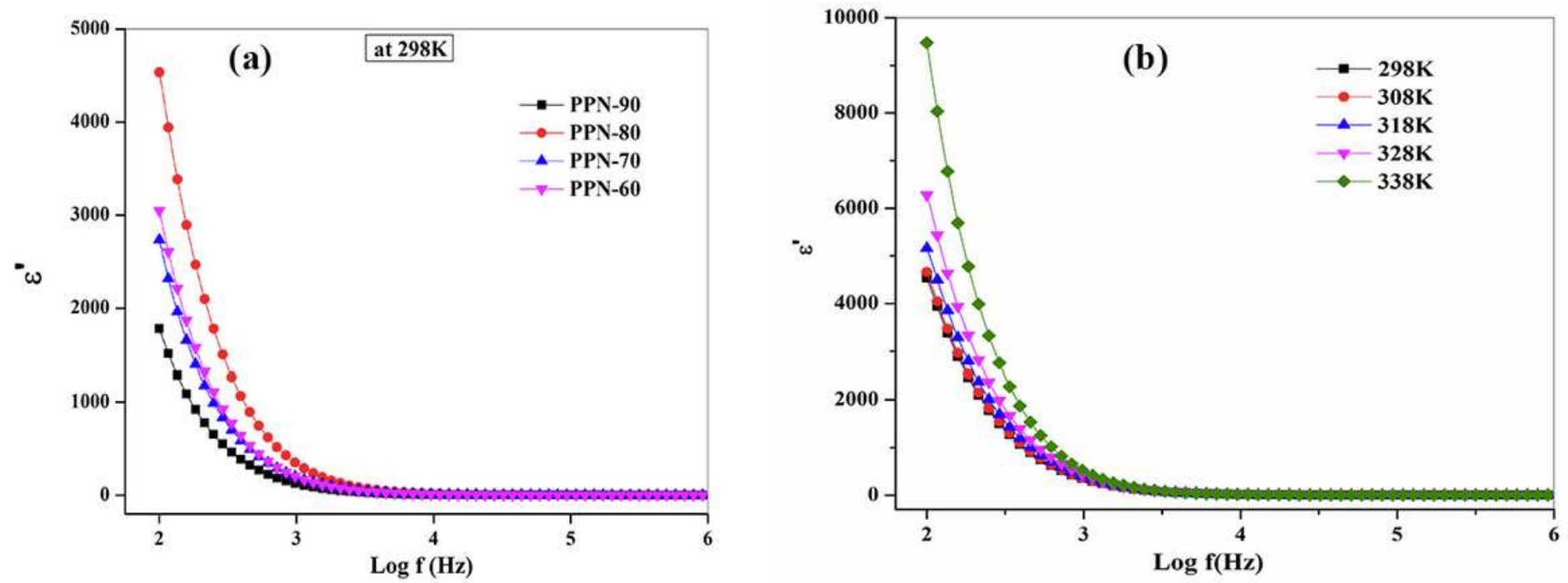

Figure 7 
Variation of Dielectric constant with frequency (a) .PPN-90, PPN-80, PPN-70 and PPN-60 at 298K (b). PPN-80 at different temperatures
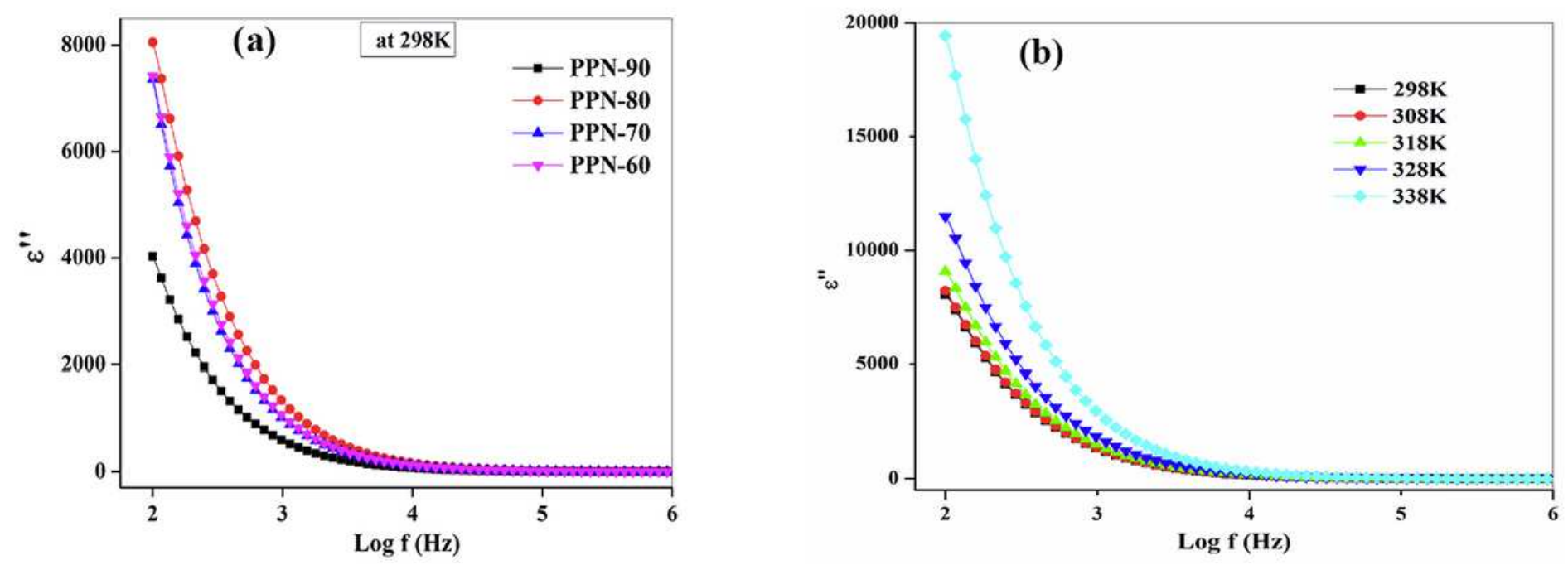

Figure 8

Variation of Dielectric loss with frequency of (a). PPN-90, PPN-80, PPN-70 and PPN-60 at 298K (b). PPN80 at different temperatures
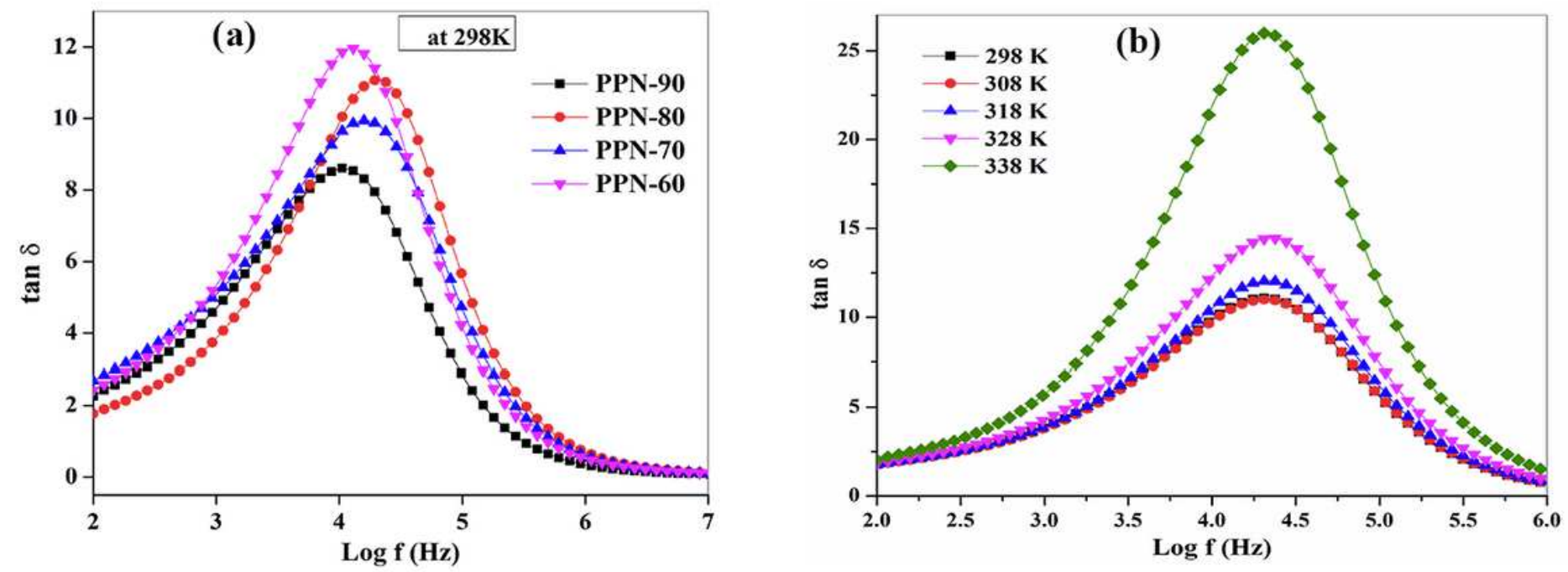

Figure 9

Variation of Tan $\delta$ with frequency of (a). PPN-90, PPN-80, PPN-70 and PPN-60 at 298K (b). PPN-80 at different temperatures 

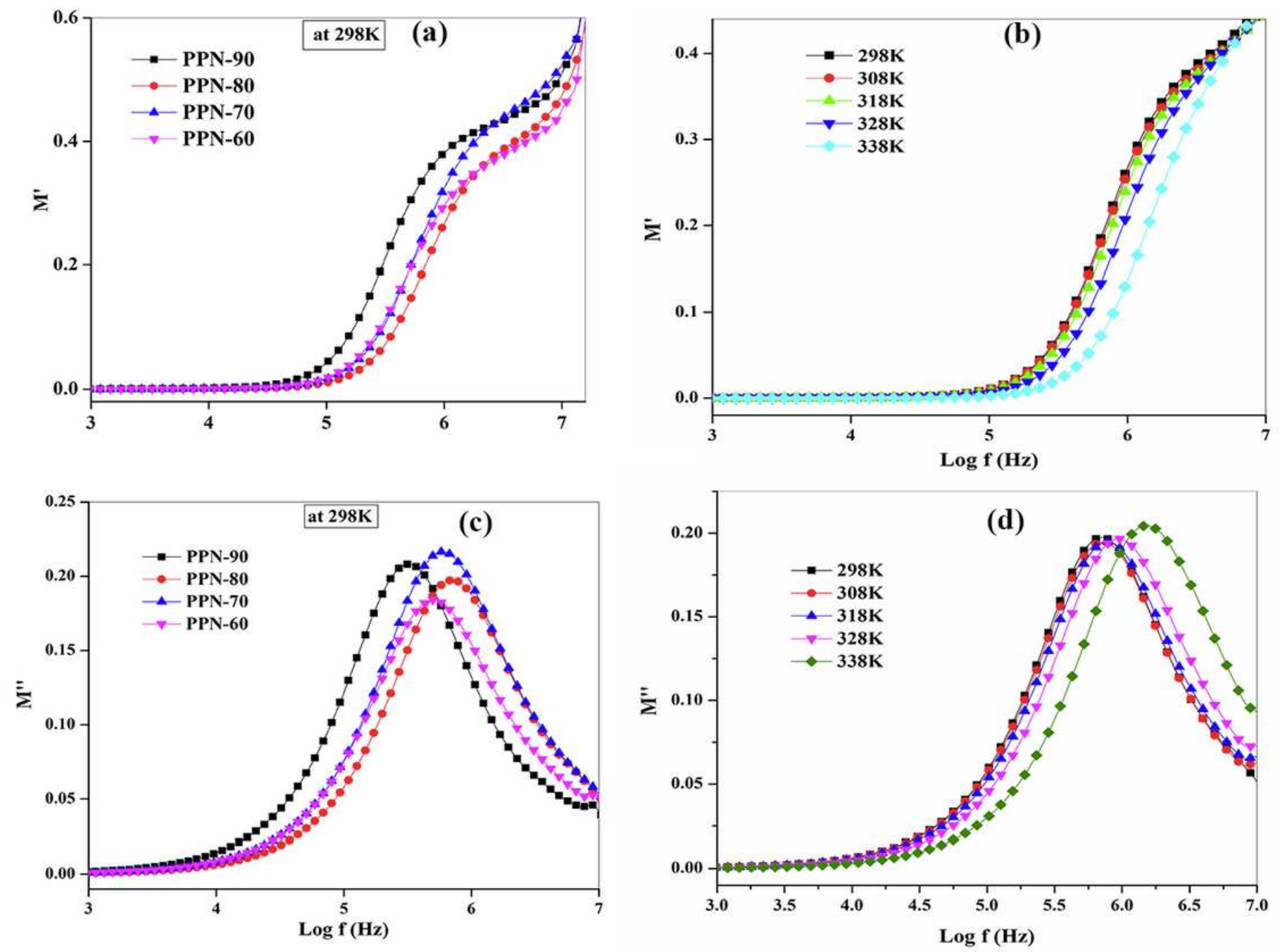

Figure 10

Variation of Real Electric modulus of (a). PPN-90, PPN-80, PPN-70 and PPN-60 samples (b). at various temperatures of PPN-80. Variation of imaginary Electric modulus of (c). PPN-90, PPN-80, PPN-70 and PPN-60 samples (d). at various temperatures of PPN-80. 